\title{
Chagas disease in the Chaco
}

\section{Researching disease transmission in poor, rural settings is part scientific inquiry, part diplomacy.}

$\mathbf{Y}$ ou would not know it if you drove to his small farm, but Ramón Raúl Alegre is the owner of a unique mud hut. It looks like all the other adobe outhouses dotted near the dusty, dirt tracks in Pampa del Indio, which is a municipality of Argentina's northerly Chaco province, except that it is more dilapidated than most. That is because the walls of Alegre's hut have been dismantled chunk by chunk, every few months, by scientists from the University of Buenos Aires (UBA) in Argentina, who are searching for the blood-sucking bug Triatoma infestans. It is the region's main vector of Trypanosoma cruzi, which is the parasite that causes Chagas disease.

The reason for this piecemeal destruction is that Alegre's hut is the first known to house bugs that somehow developed resistance to pyrethroids, the class of insecticides that has dominated vector-control programmes for Chagas disease since the mid-1980s. Curiously, the bugs developed this resistance in the absence of repeated exposure to pyrethroids. No one is sure how this happened. It is possible that the bugs were recently transported from a site in the western part of the Gran Chaco - a vast lowland plain that encompasses parts of Argentina, Bolivia and Paraguay - or that the resistance arose spontaneously in the local population.

The initial sign came when Alegre was bitten at sunset in a nearby field shortly after

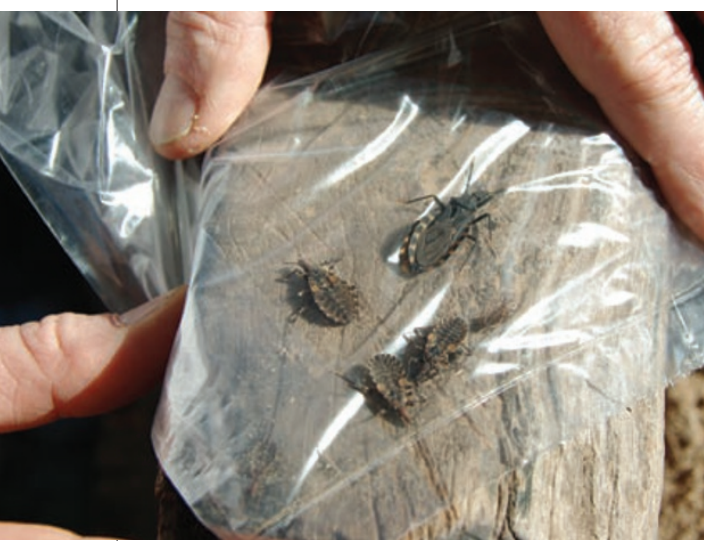

Living T. infestans collected from a chicken coop near Alegre's unique mud hut. the hut was first sprayed. This prompted an experiment. Four times at 2-monthly intervals Juan Manuel Gurevitz, a PhD student at the UBA, re-sprayed the hut with pyrethroids and collected the bugs that died. Between each application, Gurevitz placed a tent of mosquito netting over the whole structure to stop bugs escaping or re-infesting the hut and to prevent Alegre's goats from gobbling fallen insects.

"We tried all approaches to maximize pyrethroid effectiveness," says Uriel Kitron, who is a professor of environmental sciences at Emory University in Atlanta, Georgia, in the United States, and who is observing the study site. "All the time the bugs were able to reproduce and recover their numbers." Today's inspection suggests that the fifth spraying in 2 years, this time with malathion - a much more toxic insecticide that cannot be purchased over the counter in Argentina - has finally nailed Alegre's problem. The pyrethroid resistance has been confirmed by blind laboratory tests on the bugs.

\section{Life-long Chagas man}

Both Gurevitz and Kitron work with Ricardo Gürtler. Now aged 55 years, Gürtler has studied the fundamentals of Chagas disease transmission and control since he was a $\mathrm{PhD}$ student. For roughly the first half of his career, Gürtler watched with optimism as the big budget, militaristic Southern Cone Initiative interrupted vectorial transmission of Chagas disease in three of Argentina's five neighbouring countries. This happened in a few provinces of Argentina as well. After 2001, when the country experienced the largest sovereign default in economic history, however, Argentina's control programmes were degraded by inconsistent funding and vague or absent management. The number of Argentines displaying acute symptoms of Chagas disease has since risen in eight of the 22 provinces.

The bulk of Gürtler's research comes from Santiago del Estero province in Argentina, where he and his co-workers kept tabs on a study site between 1984 and 2006 (ref. 1). They have compiled a huge database. Over the years,

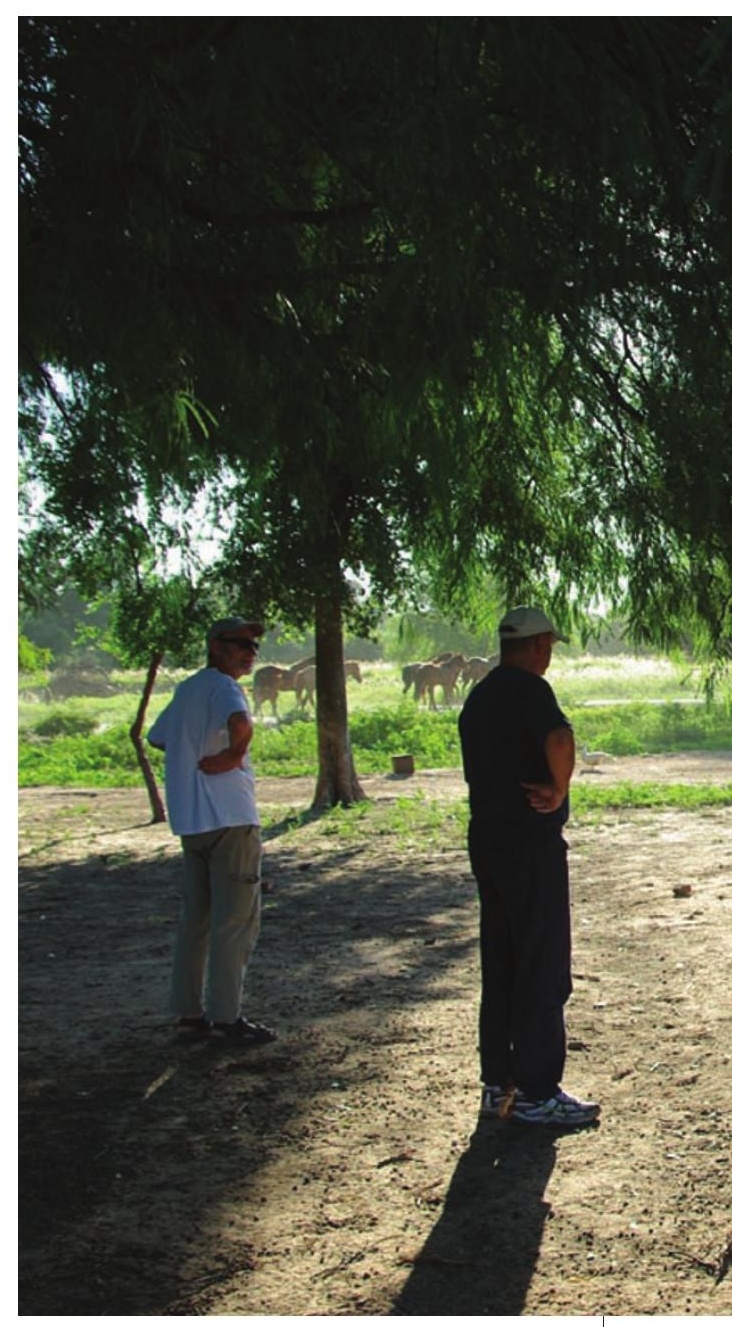

they monitored bug densities, counted how many bugs were infected at different stages of development, tested dogs, cats and residents, and organized communities to plaster the walls of some houses to eliminate the crevices that the bugs like to hide in. They used the information to model T. cruzi transmission mathematically ${ }^{2}$. Policy recommendations fell out of their models.

"For example, Ricardo showed that if you have fewer than two dogs in a household, you're unlikely to get infected," says Rick Tarleton, who is a professor at the University of Georgia and has researched Chagas disease since the 1980s. "That information has been helpful in planning dog vaccination programmes." A group at the Autonomous University of Yucatán, in Mérida, Mexico, has started testing a therapeutic DNA vaccine against T. cruzi in mongrel dogs. In 2008 , they published the results of a pilot clinical trial, which showed some success. Over the past decade, researchers have increasingly used dogs as sentinels of T. cruzi transmission, and new research has suggested that their immune reaction against bug salivary antigens can be used as a surveillance tool.

"The dog issue is a classic example of the kind of heterogeneity we keep finding with Chagas," says Kitron, as a ragged old dog limps past. "This guy's much more likely to be the 


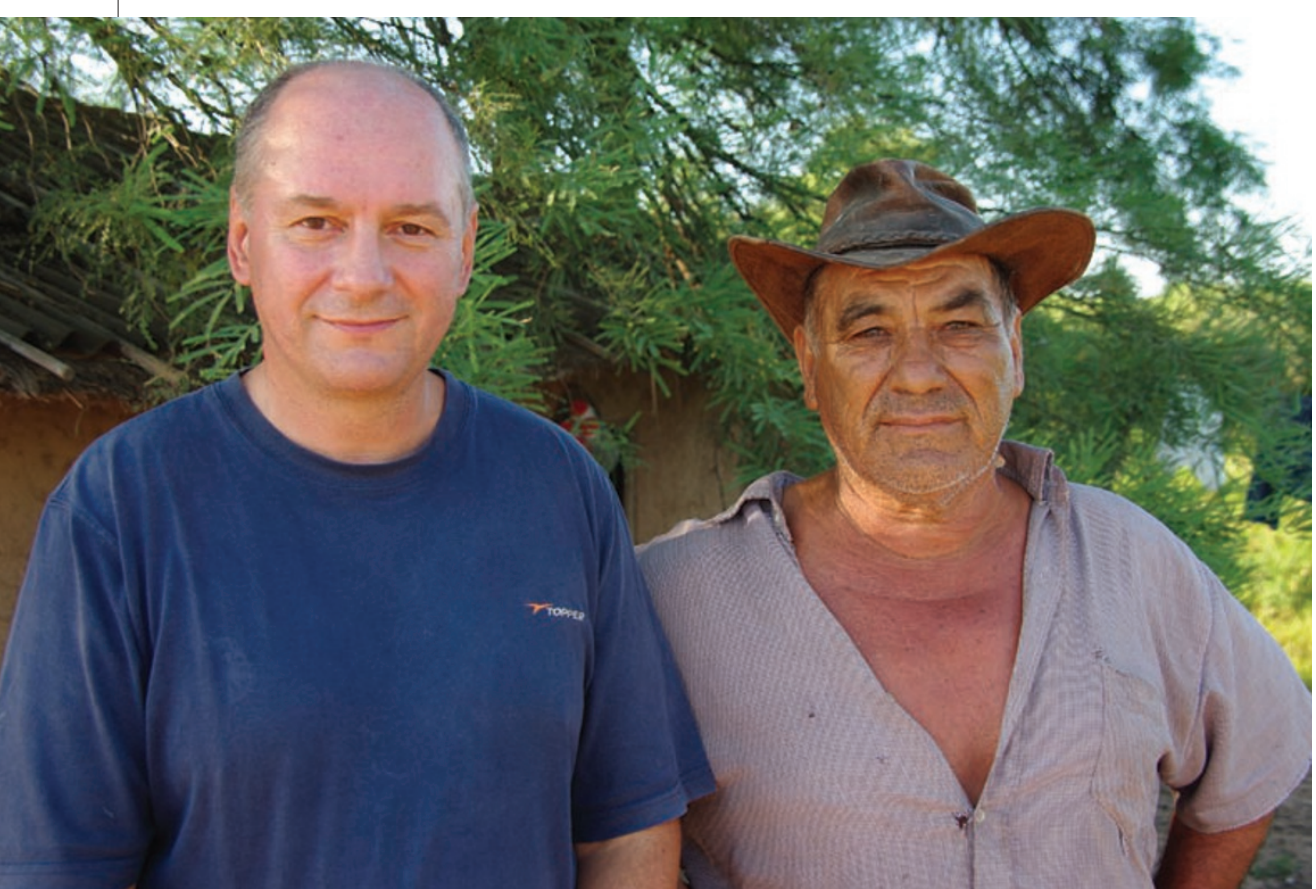

Gürtler (left) and Alegre (right).

time - and the local health-care staff can't do this because they are understaffed."

Tobas also have a different attitude towards their homes. For instance, last year, Gürtler and his team found 500-odd vectors in one house, just 15 min after spraying - which suggested that the hut could have been infested with $\sim 5,000$ bugs in total. Rather than treating the house, the family decided to burn it to the ground. "They often do the same if a relative dies in a house - burn it and build another house close by," explains Gürtler. Understanding these idiosyncrasies is part of what he calls "the human element", which Gürtler believes is neglected by most Chagas disease control programmes - a sentiment echoed by on-theground researchers in other countries (Box 1).

\section{From Chagas to Kafka}

This trip's purpose is to show Kitron around the new study site. As part of the tour, Gürtler drops in on the local hospital. It seems clean, with a committed but under-trained staff. The director, Arturo Navajas, is open about its problems. He does not have good statistics on the prevalence of Chagas disease locally. His best data are for the pregnant women who visit the hospital, of which $\sim 10 \%$ test positive. The true figure is almost certainly higher. Moreover, the hospital has only two boxes of drugs - enough for merely 15 people - that arrived a year after they were ordered.

Inefficiencies at every level beset the scientists trying to study Chagas disease. In 2002, in the middle of Argentina's economic crisis, Gürtler and Kitron received a grant from the United States National Institutes of Health, of which more than US\$500,000 went to their work in Argentina. Meanwhile, to reduce the rate at which cash left the country, the Argentine government passed a law limiting the amount of money that could be withdrawn from bank accounts to a few hundred dollars a week. This meant that Gürtler had to buy reagents and minor equipment during trips to the United States. "Even today we have to justify every dollar that enters the lab's bank account as if we were laundering money. It's really not anyone's fault," he shrugs. "It's the way everything works here. It's a kind of Kafka-esque story. People from abroad find it hard to understand. It's a challenge everywhere to get funded [...] but here dealing with how you get to the money takes about a third of researchers' time."

Like many countries in Latin America, Argentina has a decentralized public-health system. Provinces and municipalities administer vector control in a whimsically individual way. In Pampa del Indio, for example, no official is responsible for ensuring that houses are sprayed with insecticides; however, favours can sometimes be bartered. The morning after Gürtler shows Kitron the hospital, he is back to speak to Navajas. He has telephoned Hector Frelij, who is a friend of his in Buenos Aires and who has the difficult task of coordinating Chagas disease control at the national level. Frelij has agreed to send more drugs directly to Pampa del Indio. In response, Navajas says he will help Gürtler in organizing crosssectional blood tests of the community to provide an estimation of the local prevalence of the disease.

\section{The dark side of data}

Good data are scarce, and the more scientists dig, the more they seem to be debunking the assumptions upon which the Southern Cone Initiative was based. In the beginning, eliminating $T$. infestans was considered achievable because this vector was thought to be highly susceptible to pyrethroids and lacking the genetic variation required to develop resistance. Several groups, including Gürtler's, have disproved these assumptions. The bugs were also thought to be bad fliers and unable to re-infest from afar. Gürtler's data from Santiago del Estero, however, reveal that they can travel distances of 500-2,000 $\mathrm{m}^{4}$.

It was also assumed that once all of the T. infestans bugs in a settlement had been eliminated, re-infestation from nearby forests was impossible. Except for a melanic version or 'dark morph' of $T$. infestans that lives in the Andean valleys of Bolivia, T. infestans was thought to be unable to survive and breed in the wild. Again, this is untrue. In the summers of 2006 and 2007, several members of Gürtler's group identified dark morphs in forest $40 \mathrm{~km}$ from the town of Fuerte Esperanza in northeast Argentina, not far from Pampa del Indio ${ }^{5}$, and $\sim 1,000 \mathrm{~km}$ from the Andean valleys of Bolivia. They did this by piggybacking on a study of the local population of Amazona aestiva and Aratinga acuticaudata parrots. These birds tend to nest in hardwood trees with trunks made hollow by a fungus. When Gürtler's group placed jars containing live mice (as bait) in the trees, they recovered dark morphs of T. infestans glued to the sticky paper placed around the necks of the jars. The trapped bugs appear to be genetically much closer to the insects living in huts in Pampa del Indio than to the sylvatic dark morphs in Bolivia - suggesting that some of the reinfestation in the eastern Gran Chaco comes from non-domestic populations.

"It's just that no one looked for them before," suggests Gürtler. Similarly, nobody thought to study urban vectors until recently - or systematically checked, after spraying campaigns, whether the bugs really did die. These revelations point to why the original Southern Cone Initiative did not work everywhere, and give some hope that programmes can be designed to reinvigorate it.

Back at Alegre's unique mud hut, Gurevitz has found T. infestans vectors in a nearby chicken coop. It is unknown whether these originated from the resistant population in the hut or flew to the coop from another house $500 \mathrm{~m}$ away. Gürtler, Gurevitz and Kitron drive to Alegre's house to try and find him. His wife appears. "More bugs?" she asks, disappointed. "Don't worry, we'll get rid of them. We'll be back," promises Gurevitz.

\section{Anna Petherick}

\footnotetext{
Gürtler, R. E. et al. Proc. Natl Acad. Sci. USA 41, 16194-16199 (2007).

2. Cohen, J. E. \& Gürtler, R. E. Science 293, 694-698 (2001).

3. Cecere, M. C. et al. Emerg. Infect. Dis. 12, 1096-1102 (2006).

4. Vazquez-Prokopec, G. M. et al. Med. Vet. Entomol. 20,1-6 (2006).

5. Ceballos, L. A. et al. J. Med. Entomol. 46, 1195-1202 (2009).
} 